\title{
Direct Metal-free $\alpha$-Iodination of Arylketones Induced by Iodine or Iodomethane with HTIB in Ionic Liquid
}

\author{
Jong Chan Lee, Jimi Kim, Hyun Jung Park, Byungmook Kwag, and Seung Bae Lee \\ Department of Chemistry, Chung-Ang University, Seoul 156-756, Korea. ${ }^{*}$ E-mail: jclee@cau.ac.kr \\ Received May 21, 2009, Accepted March 8, 2010
}

Key Words: Iodination, Hypervalent, Ionic liquid, Ketones

$\alpha$-Iodoketones are versatile intermediates in organic synthesis. ${ }^{1-2}$ In general, $\alpha$-iodination of aryl ketones have been achieved through activation of elemental iodine with various reagents such as copper (II) acetate, ${ }^{3}$ cerium (IV) ammonium nitrate, ${ }^{4}$ mercury (II) chloride, ${ }^{5}$ and selenium dioxide. ${ }^{6}$ However, most of the reported iodine induced alpha iodination methods were conventionally required use of transition metal Lewis acids along with demanding reaction conditions. Furthermore, most of above methods generally employed strong acidic or basic conditions which inevitably accompanied undesirable formation of $\alpha, \alpha$-diiodinated side products in significant amount. Therefore, development of a mild and efficient method for mono alpha iodinated ketones is still highly desirable.

In recent years, ionic liquids have emerged as promising green reaction media for the various organic transformations due to their favorable properties such as negligible vapor pressure and low flammability. ${ }^{7}$ On the other hand, Koser's reagent [hydroxyl(tosyloxy)iodo]benzene (HTIB) has been utilized as highly versatile reagent in organic synthesis and has many advantages in organic transformations due to its nature of neutrality, high stability, and low toxicity. ${ }^{8}$ Therefore development of new greener synthetic method for the $\alpha$-iodo arylketones using HTIB in ionic liquid would be highly desirable. We deduced that the $\alpha$-iodination reaction of arylketones with suitably activated iodomethane by HTIB would provide the corresponding $\alpha$-iodo arylketones. In this case, non-metallic HTIB acts as Lewis acid to activate molecular iodine as iodonium ion $\left(\mathrm{I}^{+}\right)$ donor. Formation of iodonium ion from the in situ interaction of HTIB with iodine has been proposed previously in the oxidative rearrangement of haloethynylcarbinols to $\beta, \beta$-dihaloenones. ${ }^{10}$ However, to the best of our knowledge, utilization of molecular iodine as an $\alpha$-iodinating reagent for arylketones never has been attempted previously. Moreover, up to date, there has been no report on the $\alpha$-iodination reactions of ketones conducted in environmentally friendly ionic liquid medium.

In this paper, we wish to report the use of $\mathrm{I}_{2} / \mathrm{HTIB}$ in ionic liquid as novel system for the efficient $\alpha$-iodination of arylketones. Accordingly, treatment of HTIB with iodine (1.2 equiv) in 1-butyl-3-methylimidazolium tetrafluoroborate $\left(\left[\mathrm{bmim}^{\mathrm{B}} \mathrm{BF}_{4}\right)\right.$ ionic liquid for $1 \mathrm{~h}$, followed by reaction with aryl ketone (1.0 equiv) at $60{ }^{\circ} \mathrm{C}$ gave the corresponding $\alpha$-iodo arylketones in high yields (Scheme 1). As shown in the Table 1, both methylene ketones and methyl ketones generally provided the corresponding $\alpha$-iodo arylketones in high yields. Probably, the $\alpha$-iodination reaction proceeded by the reaction of $\mathrm{I}^{+}$, preformed through activation of iodine by HTIB, with the enol tautomer of arylketones. We next examined $\alpha$-iodination of 1,3-diketones since preparation of 2-iodo-1,3-dicarbonyl compounds were known to be difficult. ${ }^{11}$ At the present conditions, 2-iodo-1,3-diketones were also successfully obtained in high yields (entries 10-11).

Upon established iodine/HTIB system for the $\alpha$-iodination of aryl ketones, we have tested the possibility of $\mathrm{CH}_{3} \mathrm{I}$ as an iodonium ion source by the activation with HTIB. Treatment of aryl ketone with 3.0 molar equivalent of $\mathrm{CH}_{3} \mathrm{I}$ in the presence of HTIB at room temperature gave successfully the desired $\alpha$ iodo arylketones in high yields. In the contrary to aforementioned method using molecular iodine/HTIB, iodomethane/ HTIB induced reactions generally proceeded with longer reaction times $(20 \mathrm{~h})$. However, this protocol can be conducted at ambient temperature which can be of a great advantage for the practical applications. Replacement of methyl iodide by iodopropane gave much inferior results in terms of yields. In all of the cases studied with both reaction conditions, no $\alpha, \alpha$-diiodinated ketone products were observed which demonstrate the mildness of the present reaction conditions.

In summary, we have developed a new and efficient method for the preparation of $\alpha$-iodo arylketones from the reaction of arylketones with activation of molecular iodine or methyl iodide with HTIB in [bmim $] \mathrm{BF}_{4}$ ionic liquid.

Table 1. Iodination of aryl ketones with $\mathrm{I}_{2}$ or $\mathrm{CH}_{3} \mathrm{I}$ in the presence of HTIB

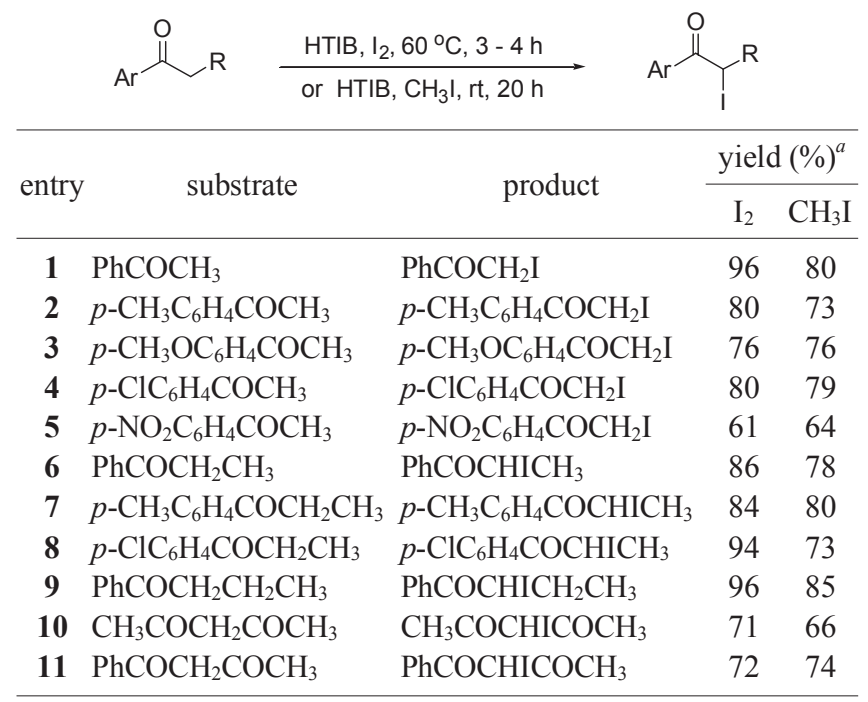

\footnotetext{
${ }^{a}$ Isolated yield.
} 


\section{Experimental Section}

The 1-butyl-3-methylimidazolium tetrafluoroborate, [bmim] $\mathrm{BF}_{4}$, was obtained from Aldrich. Merck silica gel 60 (230 - 400 mesh) was used for flash column chromatography.

Typical procedure for $\alpha$-iodination reaction of arylketones. To a solution of $\mathrm{I}_{2}(0.304 \mathrm{~g}, 1.2 \mathrm{mmol})$ in $[\mathrm{bmim}] \mathrm{BF}_{4}(1.0 \mathrm{~mL})$ was added [hydroxyl(tosyloxy)iodo]benzene $(0.392 \mathrm{~g}, 1.0 \mathrm{mmol})$ and stirred at $60{ }^{\circ} \mathrm{C}$ for $1 \mathrm{~h}$. After cooling down the reaction mixture, acetophenone $(0.120 \mathrm{~g}, 1.0 \mathrm{mmol})$ was added and the stirring was continued for $3 \mathrm{~h}$ at $60{ }^{\circ} \mathrm{C}$. After completion of the reaction, the product was extracted with dichloromethane $(2 \times$ $20 \mathrm{~mL})$, washed with $5 \%$ aqueous sodium thiosulfate $(20 \mathrm{~mL})$, and dried over $\mathrm{MgSO}_{4}$. The solvent was removed in vacuo and the crude mixture was purified by silica gel chromatography using dichloromethane as eluent to give $0.236 \mathrm{~g}(96 \%)$ of 2 iodo-1-phenylethanone. mp $33 \sim 35{ }^{\circ} \mathrm{C} ;{ }^{1} \mathrm{H}$ NMR $(300 \mathrm{MHz}) /$ $\left.\mathrm{CDCl}_{3}\right) \delta 8.02(\mathrm{dd}, J=6.2 \mathrm{~Hz}, 2 \mathrm{H}), 7.58(\mathrm{dd}, J=6.2 \mathrm{~Hz}, 1 \mathrm{H})$, 7.49 (dd, $J=6.2 \mathrm{~Hz}, 2 \mathrm{H}), 4.37$ (s, 2H).

Typical procedure for $\alpha$-iodination reaction of arylketones. To a solution of 4-chloroacetophenone $(0.155 \mathrm{~g}, 1.0 \mathrm{mmol})$ in [bmim] $\mathrm{BF}_{4}(1 \mathrm{~mL})$ was added [hydroxyl(tosyloxy)iodo]benzene $(0.392 \mathrm{~g}, 1.0 \mathrm{mmol})$ and iodomethane $(0.426 \mathrm{~g}, 3.0 \mathrm{mmol})$. The reaction mixture was stirred at room temperature for $20 \mathrm{~h}$. After completion of the reaction, the product was extracted with dichloromethane $(2 \times 20 \mathrm{~mL})$, washed with $5 \%$ aqueous so- dium thiosulfate $(20 \mathrm{~mL})$, and dried over $\mathrm{MgSO}_{4}$. The solvent was removed in vacuo and the crude mixture was purified by silica gel chromatography using dichloromethane as eluent to give $0.221 \mathrm{~g} \mathrm{(79 \% )} \mathrm{of} \mathrm{1-(4-chlorophenyl)-2-iodoethanone.} \mathrm{mp}$ $72 \sim 74{ }^{\circ} \mathrm{C} ;{ }^{1} \mathrm{H}$ NMR $\left.(300 \mathrm{MHz}) / \mathrm{CDCl}_{3}\right) \delta 7.95(\mathrm{~d}, J=11 \mathrm{~Hz}$, $2 \mathrm{H}), 7.46(\mathrm{~d}, J=11 \mathrm{~Hz}, 2 \mathrm{H}), 4.33(\mathrm{~s}, 2 \mathrm{H})$.

Acknowledgments. This research was supported by the Chung-Ang University Research Scholarship Grants in 2009.

\section{References}

1. Boyer. J. H.; Natesh, A. Synthesis 1988, 980.

2. Ji, S.-J.; Takahashi, E.; Takahashi, T. T.; Horiuchi, C. A. Tetrahedron Lett. 1999, 9263.

3. Horiuchi, C. A.; Satoh, J. Y. Synthesis 1981, 312.

4. Horiuchi, C. A.; Kiji, S. Chem. Lett. 1988, 31.

5. Barluenga, J.; Martinez-Gallo, J. M.; Najera, C.; Yus, M. Synthesis 1986, 678.

6. Bekaert, A.; Barberan, O.; Gervais, M.; Brion, J.-D. Tetraheron Lett. 2000, 41, 2903.

7. Kosower, E. M.; Cole, W. J.; Wu, G. S.; Cardy, D. E.; Meisters, G. J. Org. Chem. 1963, 28, 630.

8. Wasserscheid, P., Welton, T., Eds.; Ionic Liquids in Synthesis; Wiley-VCH: Weinheim, 2003.

9. Koser, G. F. Aldrichimica Acta 2001, 34, 89.

10. Bovonsombat, P.; McNelis, E. Tetrahedron Lett. 1992, 33, 7705.

11. Curran, D. P.; Chen, M.-H.; Spletzer, E.; Seong, C. M.; Chang, C.-T. J. Am. Chem. Soc. 1989, 111, 8872. 